\title{
Wage Dispersion and Wage Dynamics Within and Across Firms*
}

\author{
Carlos Carrillo Tudela \\ Eric Smith \\ University of Leicester \\ University of Essex
}

February 14, 2007

\begin{abstract}
This paper examines wage dispersion and wage dynamics with stock-flow matching and on-the-job search. Under stock-flow matching, a searches immediately becomes fully informed about the number of viable firms in the stock of job vacancies. If only one option is available, monopsony wages result. With more than one firm bidding, Bertrand wages arise. Over time turnover causes this historical impact to fade. Wage dispersion declines with tenure. The model also generates job-to-job transitions with both wage cuts and jumps.

JEL Classifications: J64

Keywords: Wage dispersion, wage dynamics, search, stock-flow matching
\end{abstract}

${ }^{*}$ Carrillo-Tudela: Department of Economics, University of Leicester, Astley Clarle Building, University Road, Leicester, LE1 7RH, United Kingdom, cct9@leicester.ac.uk. Smith: Department of Economics, University of Essex, Wivenhoe Park, Colchester, Essex, CO4 3SQ, United Kingdom, esmith@essex.ac.uk. 


\section{Introduction}

Competition determines wages. In frictionless markets where competition is most fierce, the outcome is straightforward. The law of one price holds and all workers are paid their marginal product. As Mortensen (2003) points out, this result is completely at odds with overwhelming empirical evidence. Similar workers are simply not paid the same wage.

In the search framework, however, matching frictions limit the extent of competition. As several studies have shown, this restriction can generate equilibrium wage dispersion among homogenous workers. The Burdett and Mortensen (1998) model, the benchmark of this approach, directly links wage dispersion to the determinants of labor turnover and wage mobility. Job and worker flows along with wage dispersion thus become key phenomena in making the search framework relevant for labor market analysis.

Although the search literature claims numerous insights, some empirical findings remain elusive and difficult to reconcile. In particular, the benchmark model predicts that the density distribution function for wages is upward sloping, there are no job-to-job transitions with wage cuts, wages do not increase without outside offers. These predictions are in stark contrast with observed behavior.

The objective of this paper is to demonstrate that these inconsistencies may stem from the underlying specification of search frictions rather than from the general search approach. The conventional approach posits a 'blackbox' random matching function to approximate search frictions. This paper instead adopts an alternative approach, the so-called stock-flow methodology, which offers not only a more rigorous and plausible microfoundation for search frictions but also a more empirically valid picture of matching dynamics. ${ }^{1}$

Under stock-flow matching, when a worker goes on the market in search of a partner, he or she immediately becomes fully informed about the number of viable firms in the stock of job vacancies. If lucky, the worker finds several viable options. If the worker is unlucky, the market turns up few and possibly

\footnotetext{
${ }^{1}$ The matching framework used here is most closely related to the stock-flow matching models of Taylor (1995), Coles (2000) and Lagos (2000). Search within a given market is "directed" as in Montgomery (1991), Moen (1997) and Acemoglu and Shimer (1999). Emerging empirical evidence indicates this framework has more validity than does the random matching. See Gregg and Petrongolo (1997), Coles and Smith (1998), Petrongolo and Pissarides (2001), Andrews and Bradley, (2001) and Kuo and Smith (2006).
} 
no viable job opportunities. In the event that no viable vacancies exist in the marketplace, the worker must wait to match from the flow of new jobs.

Consider wage determination in this set-up with on-the-job search. After the number of currently available jobs is made known, all viable firms bid for the worker services. If only one option is currently available, the firm offers a monopsony payoff that claims all of the gains to trade for the firm. On the other hand, with more than one firm involved, competitive Bertrand bidding occurs. This time, the worker extracts the gains to trade. At the outset of the employment relationship, wage dispersion thus depends on the number of competitive bidders found at that time. The number of bidders can be specified so that dispersion lines up with patterns observed in wage data.

Now suppose that at any time after a firm and worker pair up, the firm can update its offer. In other words, a new wage is offered in each period. The worker can either accept the latest offer or go again to the market to elicit bids. The firm makes its wage offer knowing that as time proceeds, firms come and go in the marketplace and the number of prospective bidders in the market evolves randomly. Random and independent birth and death processes generate turnover in the market but workers and the partnership do not know the realization of this turnover unless the worker actively engages in on-the-job search. The worker must physically visit the market to learn the actual number of bidders.

Employers who want to avoid bidding with the (anticipated) firms in the market can keep the worker away from the market with a sufficiently high wage offer. Such an offer outbids the evolving threat of on-the-job search, not the actual firms. No-search wages face two countervailing forces from turnover in the market. Previous bidders gradually leave the market. New options enter through an independent process. Outside options therefore can rise or fall depending on the birth and death process. Wages not only differ at the outset, they also evolve in different patterns.

For monopoly wages, the unfortunate history (from the worker's perspective) fades and the outside option improves. Low initial wages generally rise over time. For competitively bid wages, the more favorable history that led to high initial wages fades and eventually a less attractive expectation of the number of new firms matters more. Bertrand wages ultimately fall over time. Although wages start at different points and evolve in different patterns, they ultimately converge at long tenures. The differences from average wages resembles the ARMA process found in the error structure from panel wage regressions. 
Job availability and turnover jointly determine wage dispersion and wage dynamics. Coupled with the mechanics of the job search presented here, these factors also lead to job-to-job transitions with wage cuts and wage rises. Following the forced dissolution of a match, a worker is required to search. The probability of a finding suitable bidder depends on the most recent number of bidders and the duration of a match. For many separated workers, especially with those who had short tenures and many previous bidders, there is a high probability of finding at least one match. When a vacancy is available, a job-to-job transition takes place since all information is immediately revealed and acted upon. The wage at this new job will again depend on the realized number of bidders. For some, the realization will exceed the expectations that were pinning down the wage at dismissal. Wages in the new job will be above the old wage. For others, the realization will be below the anticipated value and the new wages in the job-to-job transition will involve a wage cut. This feature of the model fits recent evidence on wages in job-to-job transitions.

Note as well that some workers who lose there job are unlucky and do not find a new employer immediately. These workers become unemployed and must wait for new opportunities to arise. Since jobs arrive slowly, monopoly wages follow unemployment. Finding no or only one employment opportunity is most likely for those workers who had short spells of employment with employers who were paying monopoly wages. In other words, workers with the lowest pay are prone to unemployment and wage cuts when a new job is found. These workers will appear trapped in this low pat - no pay doldrums not due to their abilities but due to their history of finding it difficult locate suitable employment. ${ }^{2}$

\section{Stock-Flow Dynamics}

Consider a continuous time economy populated by a large, countable number of infinitely-lived firms, $N$, and a large countable number of infinitely-lived workers, $M$. Both agents are risk neutral, discount the future at rate $r>0$ and maximise expected lifetime payoffs.

A worker can be either employed or unemployed at any point in time.

\footnotetext{
${ }^{2} \mathrm{~A}$ number of other predictions arise in this framework but these are more difficult to verify in the data. The include initial wages below the flow utility of unemployment and wages that exceed worker productivity
} 
Unemployed workers receive payoff $b$ per unit of time. Wages of employed workers equal their outside search options as described below. Firms can also be active or dormant. From time to time, firms become endowed with new projects that produce output using a constant returns to scale technology. In all projects, a productive worker employed by a firm generates a constant flow revenue $x$ per unit of time.

Not all workers are productive in a given project. There is an idiosyncratic probability that the worker's skill set fits with the precise requirements of the job. Assume that this idiosyncratic probability is constant for all projects. Also assume that it is identical but independent across workers. Given that firms have a constant returns to scale production technology, firms can hire as many workers as it finds productive. As a result, the worker simply cares about the aggregate arrival rate of new projects that the worker fits productively. We ignore the possibility of being productive in two projects at the same firm without loss of generality.

Workers need to find out about the existence of new projects. Following the stock-flow matching approach (see Coles and Smith, 1998), information about the availability of buyers (firms) and sellers (workers) is centralized in a marketplace or "job centre". Firms post project requirements at the job centre and workers check the posted list from time to time. When the worker checks the list of posted projects, there are no frictions or delays processing the information. All information regarding the viability of a position is immediately made clear and common knowledge. As such, there are no impediments to exchange after the worker finds out about the existence of gains to trade at the job centre.

Given the worker pays a search $\operatorname{cost} c_{w} \geq 0$, he or she enters the job centre and immediately observes the number of vacancies in the market. Three relevant cases can arise:

- No vacancies are posted: the worker remains unemployed and chooses another date to re-visit the job centre.

- One vacancy is posted: the worker is hired, but the firm makes a takeit-or-leave-it offer to the worker such that it extracts the entire match rents. Let $M$ denote the expected value a worker derives from this monopsonistic offer.

- Two or more vacancies are posted: the worker is hired, but in this case, an auction among the firms takes place for the workers services. 
Bertrand bidding implies the worker captures the entire match rents. Let $B$ denote the expected value a worker derives from this offer.

During employment, the worker can decide to re-visit the job centre in search for a better offer. If on-the-job search occurs, the outcome is common knowledge. Both the worker and the firm become informed about the number of available employment opportunities for the worker in the job centre. Given this outcome, the contract is re-negotiated. The new wage depends on the number of un-sampled vacancies in the job centre at that moment.

The worker may also visit the job centre following a displacement which can occur for one of two reasons

- The firm endogenously terminates the match and dismisses the worker.

- The match ends due to exogenous job destruction, which occurs at rate $\mu .^{3}$

\section{Vacancy Turnover}

Let $t \geq 0$ denote the duration since the worker last visited the job centre. Suppose at this last visit, the worker left behind $k \geq 0$ job opportunities. More specifically, if the worker came away from this visit to the job centre either unemployed or hired monopsonistically, then $k=0$. If a competitive auction occurred, that is an auction with more than one bidder, there were $k+1$ bidders and $k \geq 1$. One bidder won the auction and the other $k$ remain behind.

Given $k$, the probability of finding $n \geq 0$ vacancies after a duration $t$ away from the job centre follows from queueing theory. In particular, this probability can be obtained from the distribution of a combination of two random variables: ${ }^{4}$

- $R V 1$ : The number of vacancies that survive until time $t$, from the number of vacancies that were left in the job centre at the time of last visit.

\footnotetext{
${ }^{3}$ In what follows matched pairs break up due to separation shocks. This occurs at a (potentially) different rate than vacant jobs being withdrawn from the marketplace. There are a number of plausible interpretations for this dichotomy that is likely to occur in the data. For these as well as some analytical reasons we allow for this distinction

${ }^{4}$ For details see Prabhu (1965).
} 
- $R V 2$ : The number of new and un-sampled vacancies in the market at time $t$, given an entry and exit process of job opportunities.

The properties of the Poisson process imply that $R V 1$ follows a Binomial distribution with parameters $\left(k, e^{-\delta t}\right)$, where $e^{-\delta t}$ is the probability that a vacancy has not left the market by time $t$. To characterize the arrival and departure of job opportunities, assume that new vacancies associated with the arrival of a new viable project for the worker enter the market at rate $\lambda$ and that vacant jobs destruction occurs as a Poisson process with rate $\delta$. It follows from the forward Kolmogorov differential equations describing this stochastic process ${ }^{5}$, that $R V 2$ has a Poisson distribution with parameter

$$
\phi(t)=\frac{\lambda}{\delta}\left(1-e^{-\delta t}\right) .
$$

As $R V 1$ and $R V 2$ are independently distributed, the probability density of their sum is given by the convolution of their respective density functions. Hence, the probability that there are $n \geq 0$ vacancies at time $t \geq 0$, given $k \geq 0$ vacancies were in the job centre at the time of last visit is described by

$$
P_{n}(t ; k)=\sum_{i=0}^{\min \{k, n\}}\left(\begin{array}{l}
k \\
i
\end{array}\right)\left(e^{-\delta t}\right)^{i}\left(1-e^{-\delta t}\right)^{k-i}\left[\frac{\phi(t)^{n-i} e^{-\phi(t)}}{(n-i) !}\right],
$$

where the $\min \{$.$\} operator applies since the convolution is not defined for$ negative factorials.

Since competitive auctions determine wages, a critical probability from an employed worker's perspective is whether or not another job opportunity exists in the market as given by $1-P_{0}(t ; k)$. For an unemployed worker, the critical probabilities are whether one job, $P_{1}(t ; k)$, or more than two jobs, $1-P_{0}(t ; k)-P_{1}(t ; k)$, have arrived. Hence, important special cases are given by

$$
\begin{aligned}
& P_{0}(t ; k)=\left(1-e^{-\delta t}\right)^{k} e^{-\phi(t)}=\left(\frac{\delta}{\lambda}\right)^{k} \phi(t)^{k} e^{-\phi(t)} \\
& P_{1}(t ; k)=P_{0}(t ; k)\left[\phi(t)+\frac{k}{\delta} \frac{\dot{\phi}(t)}{\phi(t)}\right]
\end{aligned}
$$

\footnotetext{
${ }^{5}$ For a derivation see Lemma 1 in Smith (2005).
} 
Since $P_{1}(t ; k)$ can be described as a function of $P_{0}(t ; k)$, the evolution through time of the probability of observing zero vacancies

$$
\dot{P}_{0}(t ; k)=P_{0}(t ; k) \frac{\dot{\phi}(t)}{\phi(t)}[k-\phi(t)]
$$

becomes a key determinant for describing the dynamics of wages.

\section{$3 \quad$ Worker Payoffs}

Let $E(t, k)$ represent the expected utility of an employed worker, given spell length $t$ and job opportunities $k$ as described above. Regardless of the outcome, visiting the job center at any point in time resets the employment clock to $t=0$. The payoff to on-the-job search for an employed worker is thus given by the expectation of job opportunities, $k$, knowing that the current job is always available as a fall back option:

$$
W(t ; k)=-c_{w}+\sum_{i=0}^{\infty} P_{i}(t ; k) E(0 ; i)
$$

Unemployed workers do not have an employer in hand but it is feasible and plausible that a jobless worker met a firm on the previous visit. In particular, a now displaced worker with small $k$, small $t$ and a high $c_{w}$ may not want to search straightaway in order to allow potential employers to accumulate. Given the difference in employment status, the expected value of visiting the job center for a jobless worker, $U(t ; k)$, differs accordingly:

$$
U(t ; k)=-c_{w}+P_{0}(t ; k) U(0 ; 0)+\sum_{i=1}^{\infty} P_{i}(t ; k) E(0 ; i-1)
$$

To focus on the employment relationship, the following analysis adopts the limiting case in which $c_{w} \rightarrow 0$ so that unemployed workers search immediately, or put more simply, they are always waiting in the job center.

An employed worker, on the other hand, may choose to forgo search in the current period. This depends on the wage offer from the current employer. In particular, suppose a worker is offered the wage $w(t, k)$ and the worker decides not to search this instant. With $c_{w} \rightarrow 0$, it follows that

$E(t ; k)=w(t ; k) d t+\frac{1}{1+r d t}[\mu d t U(t+d t ; k)+(1-\mu d t) \max \{E(t+d t ; k), W(t+d t ; k)\}]$ 
Moreover, if the worker also decides to forgo search in the next instant, $E(t+d t ; k) \geq W(t+d t ; k)$, we get

$$
(r+\mu) E(t ; k)=w(t ; k)+\dot{E}(t ; k)+\mu U(t ; k)
$$

The decision not to search is optimal if $E(t ; k) \geq W(t ; k)$ which clearly depends on the wage offer from the worker's existing employment opportunity. The firm can offer a sufficiently high wage such that the worker chooses or is effectively bribed not to visit the job market. The firm will naturally consider the lowest possible wage that satisfies this criteria.

A wage offer below the no-search threshold triggers a visit to the marketplace where all information is revealed. If the worker searches and finds another job, the firm finds itself bidding in an auction and can revise its offer. If the worker does not find another firm, the worker accepts the offer of the firm provided it is preferred to unemployment. For this reason, should the current firm offer a search inducing wage, it needs to pay a wage that only makes the worker better off than unemployed.

\section{Initial Payoffs}

As search resets $t$, the next step is to characterize the value functions at zero duations. Over the subsequent, small but non-zero spell length immediately following a job market visit, the worker will not expect any instaneous changes in market options. If an employer is met, the ensuing employment will not have zero spell length - prospects do not change quickly enough - so that from (4)

$$
(r+\mu) E(0 ; k)=w(0 ; k)+\dot{E}(0 ; k)+\mu U(0 ; k)
$$

If the firm finds itself in an auction for the worker, the winning bid will make the worker indifferent between soliciting more offers and accepting. If the firm is the only bidder for the worker, the firm must entice the worker out of unemployment.

Over any sustained period of no on-the-job search (no matter how short), $E(t ; k)=W(t ; k)$ and hence

$$
\dot{E}(t ; k)=\dot{W}(t ; k)=\sum_{i=0}^{\infty} \dot{P}_{i}(t ; k) E(0 ; i)
$$


The above payoffs coupled with this condition imply that $U(0 ; k)=E(0 ; k-$ 1) and hence

$$
(r+\mu) E(0 ; k)=w(0 ; k)+\sum_{i=0}^{\infty} \dot{P}_{i}(0 ; k) E(0 ; i)+\mu E(0 ; k-1)
$$

After a visit to the market all information is revealed implying that the distribution of available firms is degenerate at $k$. The birth and death process of potential jobs at that instant involves simple one step instantenous transitions:

$$
\dot{P}_{i}(0 ; k)=0 \quad \forall i \notin\{k-1, k, k+1\}
$$

and

$$
\begin{aligned}
\dot{P}_{k-1}(0 ; k) & =\delta k \\
\dot{P}_{k}(0 ; k) & =-\delta k-\lambda \\
\dot{P}_{k+1}(0 ; k) & =\lambda
\end{aligned}
$$

Plugging $\dot{P}_{i}(0 ; k)$ the value function for employment gives

$$
\begin{aligned}
(r+\lambda) E(0 ; 0) & =w(0 ; 0)+\lambda E(0 ; 1) \\
(r+\mu+\lambda+\delta k) E(0 ; k) & =w(0 ; k)+(\mu+\delta k) E(0 ; k-1)+\lambda E(0 ; k+1) \quad k \geq 1
\end{aligned}
$$

This leaves the second order non-linear difference equation

$E(0 ; k)=\frac{1}{\lambda}\{[r+\mu+\lambda+\delta(k-1)] E(0 ; k-1)-[\mu+\delta(k-1)] E(0 ; k-2)-w(0 ; k-1)\}$

The boundary condition is that a one firm auction yields the monopoly offer of unemployment $E(0 ; 0)=b / r$. Plugging it gives

$$
E(0 ; 1)=\frac{(r+\lambda) M-w(0 ; 0)}{\lambda}
$$

It is thus possible to solve this difference equation interatively starting with $E(0 ; 0)$ and $E(0 ; 1)$ given the starting wages. This solution should coverge to the second boundary condition that a worker with many firms gets productivity payments indefinitely:

$$
\lim _{k \rightarrow \infty} E(0 ; k)=w(0 ; \infty) / r=x / r
$$




\section{A Simplifying Approximation}

As wages $w(0, k)$ are unknown at this point, we adopt an approximate solution for (5) rather than solve explicitly. First note that during the course of an indefinite match, the expected surplus is $B=x /(r+\mu)$. Since workers capture the entire gains to trade when there is more than one firm bidding, it immediately follows that

$$
x / r \geq E(0, k) \geq B=x /(r+\mu) \forall k \geq 1
$$

Also note that for low rates of job destruction, that is, $\delta, \mu$ become vanishingly small, there is no prospect of any viable job disappearing. The exact solution for the second order difference equation becomes is a step function

$$
\begin{aligned}
& E(0,0)=M=b / r \\
& E(0 ; k)=\frac{x}{r} \quad \forall k \geq 1
\end{aligned}
$$

For this reason we use the lower bound $B$ for $k \geq 1$ and $M$ for $k=0$.

This outcome is readily interpreted as the extemes of one-shot monopoly and Betrand competition. Three relevant cases:

- no vacancies so worker receives payoff $U(0 ; 0)$

- one vacancy is available: firm makes monopsonistic, take-it-or-leave-it offer, $M$, that extracts entire match rents

- two or more vacancies are available: auction among the firms with Bertrand bidding so that worker captures entire current match rents $B$

The actual difference of $E(0, k)-B$ comes from payoffs when displaced. Higher $k$ confers a better search prospect.

As noted above, the critical probability for an employed worker is whether another opportunity exists:

$$
1-P_{0}(t ; k)
$$

Critical probabilities for an unemployed or displaced worker are

- whether one job has arrived, $P_{1}(t ; k)$,

- two or more jobs, $1-P_{0}(t ; k)-P_{1}(t ; k)$. 
Special cases are given by

$$
\begin{aligned}
& P_{0}(t ; k)=\left(1-e^{-\delta t}\right)^{k} e^{-\phi(t)}=\left(\frac{\delta}{\lambda}\right)^{k} \phi(t)^{k} e^{-\phi(t)} \\
& P_{1}(t ; k)=P_{0}(t ; k)\left[\phi(t)+\frac{k}{\delta} \frac{\dot{\phi}(t)}{\phi(t)}\right]
\end{aligned}
$$

Evolution through time of the probability of observing zero vacancies

$$
\dot{P}_{0}(t ; k)=P_{0}(t ; k) \frac{\dot{\phi}(t)}{\phi(t)}[k-\phi(t)]
$$

\section{Wage Offers}

We now turn to wage determination. As noted above, firms offer one of only two wages. Either the firm pays the lowest wage such that the worker prefers not to go on the market and search for other competing firms or the current firm risks job search and offers the lowest possible wage that the worker is willing to accept. Of course, if the worker finds another job, the firm finds itself in an auction and can revise its offer. This leads to zero payoff to the firm as the worker captures the entire gains from trade. Any other wage offer only generates lower profits.

Given the approximate, lower bound solution, the value functions become:

$$
\begin{aligned}
& W(t ; k)=-c+P_{0}(t ; k) M+\left[1-P_{0}(t ; k)\right] B \\
& =-c+B-P_{0}(t ; k)[B-M] \\
& U(t ; k)=B-\left(P_{0}(t ; k)+P_{1}(t ; k)\right)[B-M] \\
& (r+\mu) E(t ; k)=w(t ; k)+\dot{E}(t ; k)+\mu U(t ; k)
\end{aligned}
$$

Given wages that generate indifference between on-the-job search and maintained employment, the evolution of

$$
\dot{E}(t, k)=\dot{W}(t, k)=-\dot{P}_{0}(t ; k)[B-M]
$$

yields

$$
w(t ; k)=r B+\left(\dot{P}_{0}(t ; k)+\mu P_{1}(t ; k)-r P_{0}(t ; k)\right)[B-M]
$$


for all $k \geq 0$ and for all $t \in[0, T]$. Plugging in for $\dot{P}_{0}$ as well as $P_{1}$ from (2) and (3) and then manipulating produces

$$
\begin{aligned}
w(t ; k) & =r B+P_{0}(t ; k)\left\{\frac{\dot{\phi}(t)}{\phi(t)}[k-\phi(t)]+\mu\left[\phi(t)+\frac{k}{\delta} \frac{\dot{\phi}(t)}{\phi(t)}\right]-r\right\}[B-M] \\
& =r B+P_{0}(t ; k) \frac{\delta+\mu}{\delta}\left\{\frac{\dot{\phi}(t)}{\phi(t)}[k-\phi(t)]+\frac{\mu \lambda-r \delta}{\delta+\mu}\right\}[B-M]
\end{aligned}
$$

where use has been made of

$$
\mu \phi(t)-\dot{\phi}(t)=\frac{\mu \lambda}{\delta}-\frac{\delta+\mu}{\delta} \dot{\phi}(t)
$$

The wage $w(t ; k)$ describes the wage that induces workers not to search.

\section{Employment Duration}

A firm whose employee does not search receives profit

$$
x-w(t ; k) \leq \mu B-\left(\dot{P}_{0}(t ; k)+\mu P_{1}(t ; k)-r P_{0}(t ; k)\right)[B-M]
$$

since $B \geq x /(r+\mu)$. The match payoff must be at least as great as the option of receiving the expected productivity from indefinite employment.

The firm's payoff to an employment of duration $T$ given $k$ can be written as

$$
H(T ; k)=\int_{0}^{T}[x-w(t ; k)] e^{-(r+\mu) t} d t+e^{(-r+\mu) T} P_{0}(T ; k) H^{*}
$$

where $H^{*}=H\left(T^{*} ; 0\right)$ and $T^{*}$ represents the optimal employment duration of employment. After a spell of employment of length $T$, the firm induces the worker to search. If the worker is unlucky and does not find another employer, the auction yields the monopsony outcome with the firm obtaining the entire gains from trade and the worker none. If the worker is fortunate enough to find a rival bidder, the payoffs are reversed with the worker capturing the entire gains to trade and the firm none.

Differentiating the firm's payoff with respect to employment duration gives

$$
H_{T}(T ; k)=e^{-(r+\mu) T}\left\{x-w(T ; k)-\left[(r+\mu) P_{0}(T ; k)-\dot{P}_{0}(T ; k)\right] H^{*}\right\}
$$


By definition, the gains to trade must satisfy $B=M+H^{*}$. Given this equality and letting the inequality for $x-w(t ; k)$ hold as an equality, it then follows that

$$
\begin{aligned}
H_{T}(T ; k) & =\mu e^{-(r+\mu) T}\left\{B-\left(P_{0}(T ; k)+P_{1}(T ; k)\right)[B-M]\right\} \\
& =\mu e^{-(r+\mu) T}\left\{\left[1-\left(P_{0}(T ; k)+P_{1}(T ; k)\right)\right] B+\left[P_{0}(T ; k)+P_{1}(T ; k)\right] M\right\}>0
\end{aligned}
$$

This inequality establishes the following claim.

Claim 1 The firm never induces worker search and allows for indefinite employment. $\left(T^{*}=\infty\right.$.)

\section{$6 \quad$ Properties of $w(t ; k)$}

The Poisson arrival process of employment opportunities dictates that unemployed workers who are visiting the job centre every day do not encounter more than one employer at any given time. This implies that all workers who have a non-zero spell of unemployment receive the wage

$$
w(0,0)=r M-\lambda[B-M]<r M
$$

Unemployed workers who become employed initially receive less remuneration in employment than they received during unemployment. The expectation of receiving higher wages in the future balances this wage cut so that the worker is just indifferent between unemployment and monopsony employment. Of course, if unemployed workers did not always search, some would find more than one job available at the job centre in which case their wages would be considerably higher.

Although firms do not initiate a job termination, separations occur exogenously at rate $\mu$. When these shocks occur, the worker observes $n$ available job opportunities with probability $P_{n}(t ; k)$. If the worker does not find at least one job opportunity in the market $(n=0)$, unemployment occurs, and the worker gets payoff $U(0,0)=M$. If an employment opportunity exists $(n \geq 1)$, the worker immediately becomes employed with wages given by $w(0, n-1)$.

Some workers will be fortunate and find more than one jobs have accumulated in the market. If the worker finds exactly two job opportunities, $n=2$, the starting wage is given

$$
w(0,1)=r B+(\delta+\mu)[B-M]=\frac{r+\delta+\mu}{r+\mu} x-\frac{\delta+\mu}{r} b
$$


Note that this wage can be greater than $x$ for some parameter values. For $n \geq 3$, the starting wage is

$$
w(0, n-1)=r B=\frac{r x}{r+\mu}<x .
$$

It is easy to verify that $w(0,1)>w(0, n-1)$. Although, initial wages are one of three values, as the employment spell becomes long wages converge to

$$
w(\infty, k)=r B+e^{-\lambda / \delta}\left(\frac{\mu \lambda}{\delta}-r\right)[B-M]<x,
$$

where the inequality regarding $x$ comes from noting that $\left[1-(\lambda / \delta) e^{-\lambda / \delta}\right]>0$. That is, wage dynamics imply that there is regression to the mean over the long run.

Now consider the evolution over time of wages, given $k$, as illustrated in Figure $1 .{ }^{6}$ Differentiation of $w(t ; k)$ gives

$$
\dot{w}(t ; k)=\begin{gathered}
\left\{\dot{P}_{0}(t ; k)\left[\frac{\dot{\phi}(t)}{\phi(t)} k \frac{\delta+\mu}{\delta}-\dot{\phi}(t)+\mu \phi(t)-r\right]+\right. \\
\left.P_{0}(t ; k)\left[\frac{\ddot{\phi}(t) \phi(t)-\dot{\phi}(t)^{2}}{\phi(t)^{2}} k \frac{\delta+\mu}{\delta}-\ddot{\phi}(t)+\mu \dot{\phi}(t)\right]\right\}[B-M]
\end{gathered}
$$

Using

$$
\begin{aligned}
\mu \phi(t)-\dot{\phi}(t) & =\frac{\mu \lambda}{\delta}-\frac{\delta+\mu}{\delta} \dot{\phi}(t) \\
\mu \dot{\phi}(t)-\ddot{\phi}(t) & =(\delta+\mu) \dot{\phi}(t)
\end{aligned}
$$

we get

$\dot{w}(t ; k)=P_{0} \frac{\dot{\phi}}{\phi} \frac{\delta+\mu}{\delta}\left[(k-\phi)\left[\frac{\dot{\phi}}{\phi}(k-\phi)+\frac{\lambda \mu-r \delta}{\delta+\mu}\right]-\left(\delta+\frac{\dot{\phi}}{\phi}\right) k-\dot{\phi}(k-\phi)+\delta \phi\right][B-M]$

\footnotetext{
${ }^{6}$ It is possible to examine the distribution of wages through numerical methods.Let $N(t, k)$ describe the number of workers in the job centre such that their last visit was $t$ periods ago and left $k$ firms. Since there is no search costs, $N(0,0)$ describes the number of unemployed workers. Otherwise, $N(t, k)$ describes the number of workers with characteristics $t$ and $k$ that have just experienced a displacement shock. Letting $G(t, k)$ describes the number of workers earning a wage $w(t, k)$ in the economy we have that

$$
G(t, k)=e^{-\mu t} \sum_{n=0}^{\infty}\left[\int_{0}^{\infty} P_{k+1}(s, n) N(s, n) d s\right]
$$

where $e^{-\mu t} P_{k+1}(s, n) N(s, n)$ gives the number of workers in the job centre $t$ periods ago with characteristics $s$ and $n$ that have not been displaced.
} 
where subscripts for $t$ and $k$ are for now suppressed. Further manipulation reveals that wage progression in employment is given by

$$
\dot{w}(t ; k)=P_{0} \frac{\dot{\phi}}{\phi} \frac{\delta+\mu}{\delta}\left\{\frac{\dot{\phi}}{\phi} k(k-1)-\dot{\phi}(2 k-\phi)-(k-\phi) \frac{\delta}{\delta+\mu}\left(r+\delta+\mu-\frac{\mu \lambda}{\delta}\right)\right\}[B-M] .
$$

For sufficiently large employment duration and sufficiently fast arrival rate of vacancies, monopsony wages are hump shaped: $\dot{w}(t ; 0) \leq 0$ if and only if

$$
\lambda>\frac{\delta(r+\delta+\mu)}{\mu\left(1-e^{-\delta t}\right)-\delta e^{-\delta t}}>\frac{\delta(r+\delta+\mu)}{\mu}
$$

At the start of any employment relation, (6) implies that wage dynamics strongly depend on the number of competitors the current employer had in the job centre.

$$
\begin{gathered}
\dot{w}(0 ; 0)=\{\lambda+r+\delta+\mu\}[B-M]>0 \\
\dot{w}(0,1)=-\delta\{2 \lambda+r+\delta+\mu\}[B-M]<0 \\
\dot{w}(0,2)=2\left(\frac{\delta}{\lambda}\right)^{2} \frac{\delta+\mu}{\mu}[B-M]>0 \\
\dot{w}(0, k \mid k \geq 3)=0 .
\end{gathered}
$$

However, it is not surprising that wages eventually become flat

$$
\lim _{t \rightarrow \infty} \dot{w}(t ; k)=0,
$$

as we our previous derivations show that their is regression to the mean for large enough $t$.

Note that since for $k \geq 1$ starting wages are strictly above $w(\infty, k)$ but strictly below $w(\infty, k)$ for $k=0$, the above analysis imply that wages may well not be monotonic. More remarkably, wages may exceed productivity as demonstrated by the following claim.

Claim 2 For $k=0, w(t ; k)<x$. For $k \geq 1, \mu$ sufficiently small, and

$$
r \leq \frac{\delta e^{-\delta t}}{1-e^{-\delta t}}\left[k-\frac{\lambda}{\delta}\left(1-e^{-\delta t}\right)\right]
$$

then $w(t, k)>x$ 
Proof:

$$
\begin{aligned}
x-w(t ; k) & =\mu B-\left(\dot{P}_{0}(t ; k)+\mu P_{1}(t ; k)-r P_{0}(t ; k)\right)[B-M] \\
\lim _{\mu \rightarrow 0} x-w(t ; k) & =-\left(\dot{P}_{0}(t ; k)-r P_{0}(t ; k)\right)[B-M] \\
& =-P_{0}(t ; k)\left(\frac{\dot{\phi}}{\phi}(k-\phi)-r\right)[B-M] \\
& =-P_{0}(t ; k)\left(\frac{\delta e^{-\delta t}}{1-e^{-\delta t}}\left[k-\frac{\lambda}{\delta}\left(1-e^{-\delta t} \phi\right)-r\right]\right)[B-M]<0
\end{aligned}
$$

given $r \leq \frac{\delta e^{-\delta t}}{1-e^{-\delta t}}\left[k-\frac{\lambda}{\delta}\left(1-e^{-\delta t}\right)\right]$

Note that $\lim _{\mu \rightarrow 0} x-w(0 ; k)=0$ as $P(0 ; k)=0$ for $k \geq 1$. For $k=0$,

$$
\begin{aligned}
x-w(t ; 0)= & \left\{\mu\left[1-P_{1}(t ; 0)\right]-\dot{P}_{0}(t ; 0)+r P_{0}(t ; 0)\right\} B \\
& +\left(\dot{P}_{0}(t ; 0)+\mu P_{1}(t ; 0)-r P_{0}(t ; 0)\right) M \\
= & \left\{\mu\left[1-P_{1}(t ; 0)\right]+(r+\dot{\phi}(t)) P_{0}(t ; 0)\right\} B \\
& +\left(\dot{P}_{0}(t ; 0)+\mu P_{1}(t ; 0)-r P_{0}(t ; 0)\right) M
\end{aligned}
$$

If $x-w(t ; k)<0$, then

$$
\dot{P}_{0}(t ; 0)+\mu P_{1}(t ; 0)-r P_{0}(t ; 0)>0
$$

which implies that

$$
x-w(t ; 0)>\left\{\mu\left[1-P_{1}(t ; 0)\right]+(r+\dot{\phi}(t)) P_{0}(t ; 0)\right\} B>0 .
$$

\section{Numerical Simulations}

We simulate (6) for several parameter values. Namely, we allow $k=$ $[0,1,2,10,20,30]$. Following Postel-Vinay and Robin (2002), we set the rate of job destruction to $\mu=0.006$ and the time discount rate to $r=0.05$. For the vacancy creation rate we assume $\lambda=0.07$. We use three values for the vacancy destruction rate $\delta=[0.04,0.07,0.1]$ to show how wage dynamics change as the turnover rate in the job centre, $\lambda / \delta$, changes. The rest of parameter are chosen arbitrarily: $p=50$ and $b=10$. 


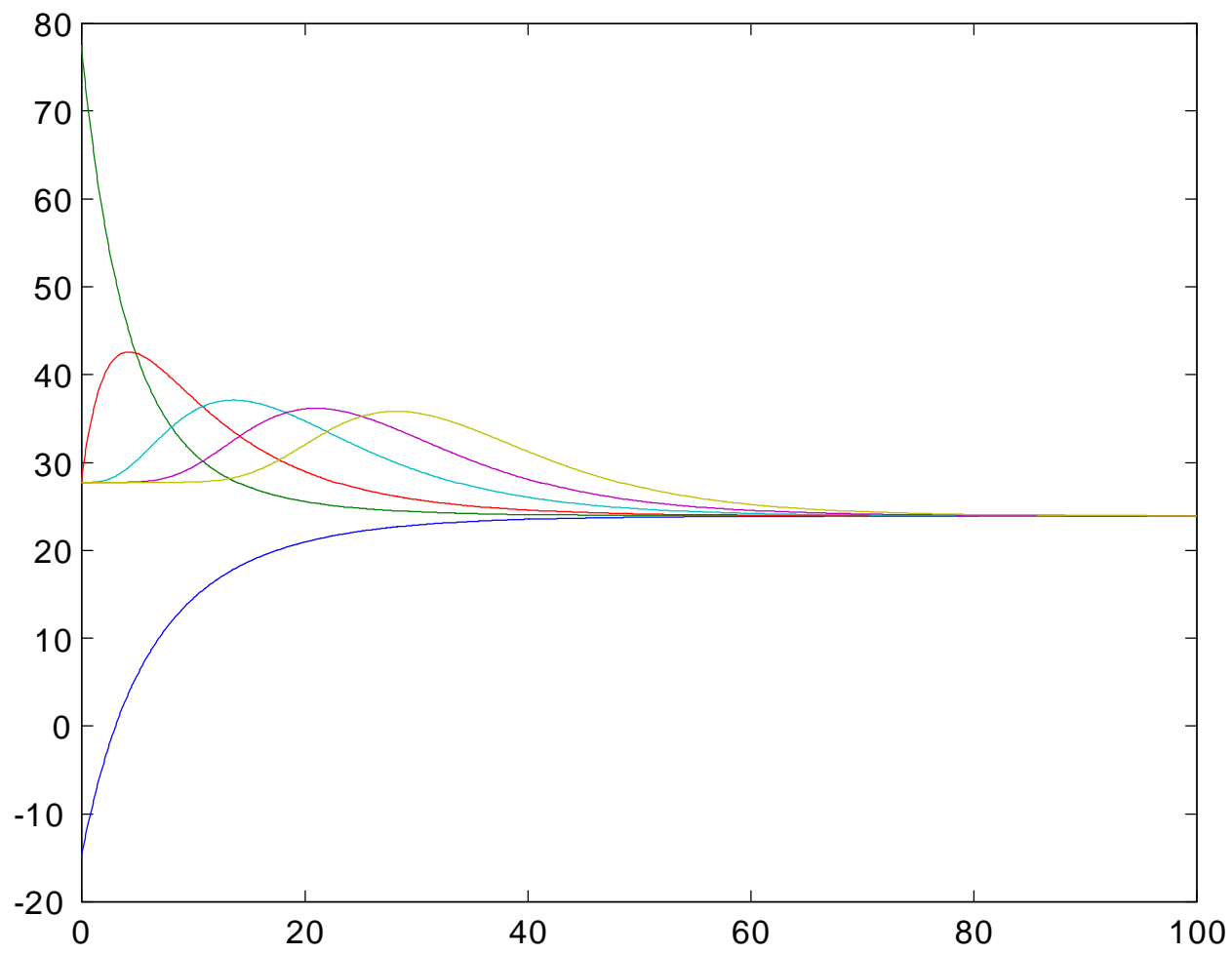

Figure 1: Wage dynamics when $\delta=0.1$ 


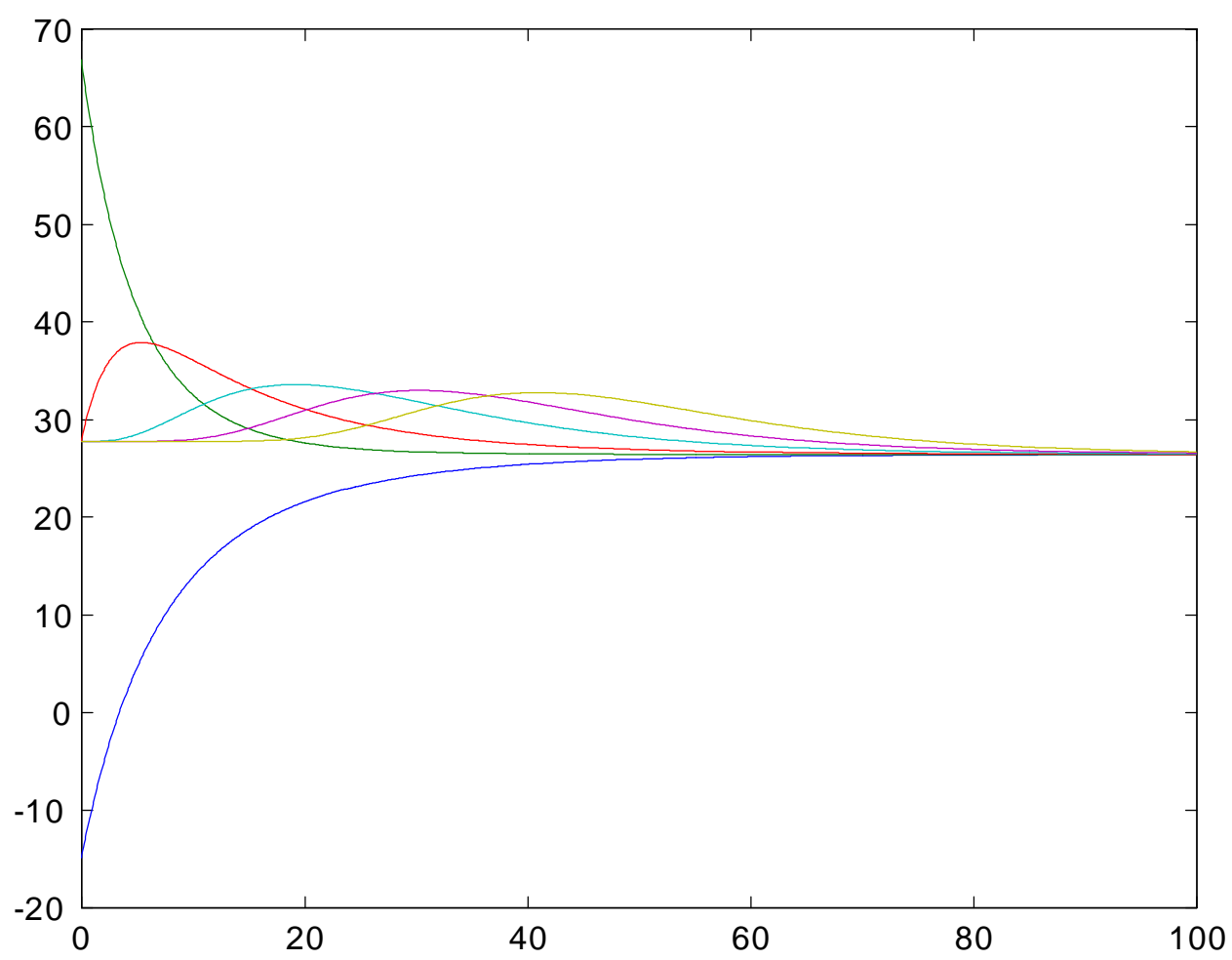

Figure 2: Wage dynamics when $\delta=0.07$ 


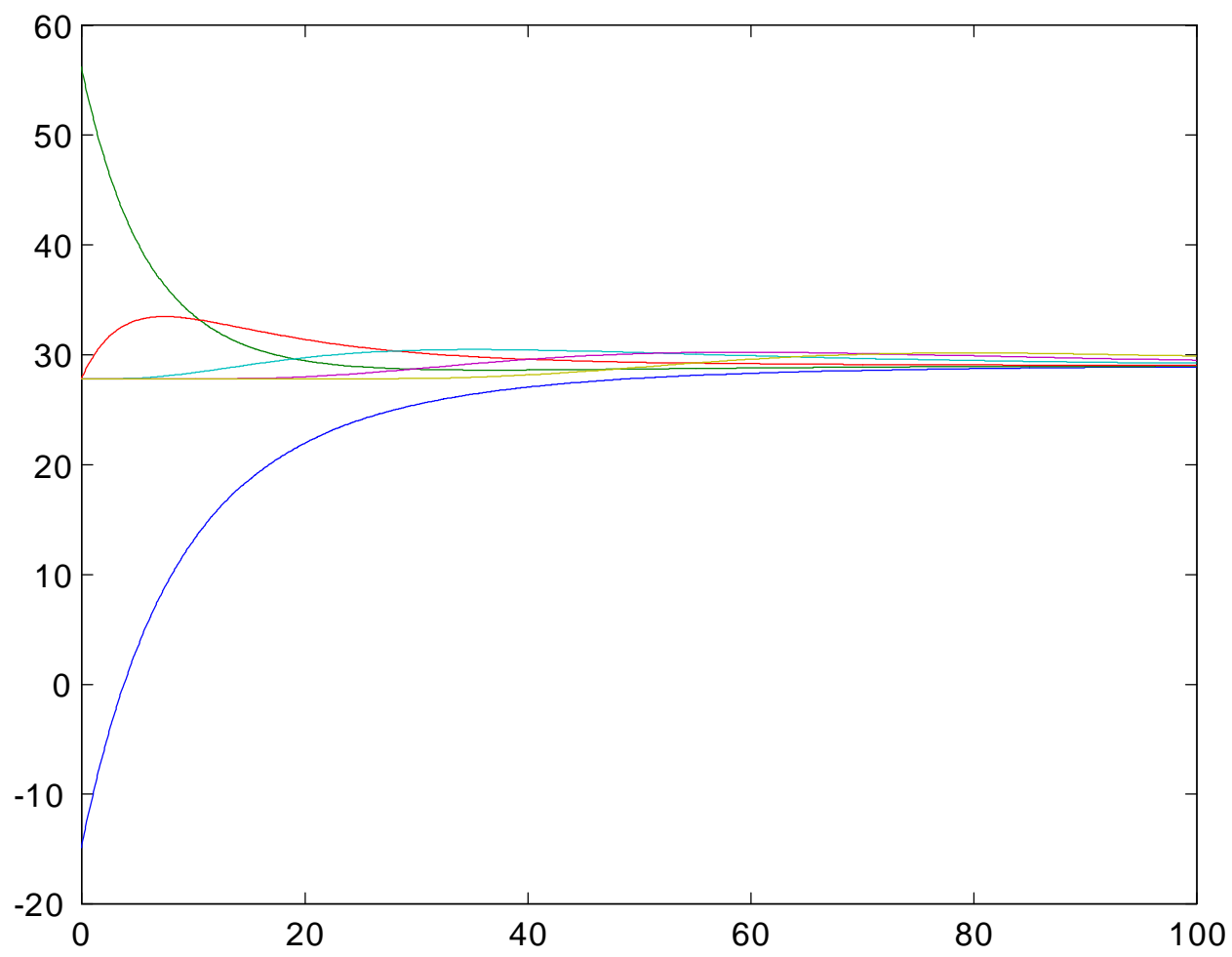

Figure 3: Wage dynamics when $\delta=0.04$ 
First note that for these set of parameter values we obtain a rich description of wage dynamics. When $k=0$, wages start below $b$ and then increase in a concave fashion. After crossing $w(\infty, k)$, they tend to converge to this value. In the case of $k=1$, wages tend to decrease in a convex fashion towards their stationary value. When $k \geq 2$, the "hump" in the wages shifts to the right as $k$ increases. After this peak, wages tend to converge to their stationary value.

\section{Job-to-Job Transitions}

A displaced worker who visits the market and encounters $n=0$ bidders becomes unemployed. A realization of $n \geq 1$, leads to immediate re-employment. Unlike conventional search models, separation shocks $\mu$ can readily be connected with job-to-job transitions. Starting from low monopsony wages, that is $w(t, 0)<r B$, job-to-job transitions will involve a wage rise provided the realization of $n$ is greater than equal to two bidders. A wage fall follows when $n=1$. Both outcomes are observed in the data.

The job-to-job wage wage transitions following more competitve wages can also rise or fall. Given the above wage progressions at the start of employment for $k \geq 1$, job-to-job transitions can involve lower wages for not only workers with any $k$ who observe $n=1$, but also for workers with who observe $n \geq 2$. Similarly, wage increases following a separation shock can rise provided $n \geq 2$. The exact nature of the changes will depend on the wages which are a function employment duration, $t$, and previous untaken vacancies, $k$.

The wages changes occur as realizations of search can either exceed or fall short of the expectations governing search. As current wages anticipate the realization from search, it follows that low pay and no pay outcomes appear tied closely together. Put simply, low wage workers are more likely to become low wage or unemployed. These realizations fade only as employment endures.

\section{References}

[1] Acemoglu, D. and Shimer, R. (1999), "Efficient Unemployment Insurance", Journal of Political Economy, 107, 893-929. 
[2] Andrews, M., Bradley, S. and Upward, R. (2001), "Estimating the Probability of a Match Using Microeconomic Data for the Youth Labour Market", Labour Economics, 8, 335-357.

[3] Burdett, K. and Mortensen, D. (1998) "Wage differentials, employer size, and unemployment", International Economic Review 39, 257-273.

[4] Coles, M. (1999), "Turnover Externalities with Marketplace Trading", International Economics Review, 40, 851-867.

[5] Coles, M. and Smith, E. (1998), "Marketplaces and Matching", International Economic Review, 39, 239-255.

[6] Gregg, P. and Petrongolo, B. (1997), "Random or Non-Random Matching? Implications for the Use of the UV Curve as a Measure of Matching Effectiveness", Institute for Economics and Statistics (Oxford) Discussion Paper No. 13.

[7] Kuo, M. and Smith, E. (2006), "Marketplace Matching in Britain: Evidence from Individual Unemployment Spells", mimeo, University of Essex.

[8] Lagos, R. (2000), "An Alternative Approach to Search Frictions", Journal of Political Economy, 108, 851-73.

[9] Moen, E. (1997), "Competitive Search Equilibria", Journal of Political Economy, 105, 385- 411.

[10] Montgomery, J. (1991), "Equilibrium Wage Dispersion and Interindustry Wage Differentials", Quarterly Journal of Economics, 106, 163-179.

[11] Mortensen, D., (2003). Wage Dispersion. Zeuthen Lecture Book Series, Cambridge.

[12] Petrongolo, B. and Pissarides, C. (2000), "Looking Inside the Black Box: A Survey of the Matching Function", Journal of Economic Literature, $34,390-431$

[13] Postel-Vinay, F. and Robin, J-M. (2002), "The Distribution of Earnings in a Equilibrium Search Model with State-Dependent Offers and Counteroffers", International Economic Review, 43, 4, 989-1016. 
[14] Prabhu, N. (1965), "Queues and Inventories: A Study of their Basic Stochastic Processes", Wiley.

[15] Smith, E. (2007) "Limited Duration Employments", Review of Economic Dynamics, in press.

[16] Taylor, C. (1995), "The Long Side of the Market and the Short End of the Stick: Bargaining Power and Price Formation in Buyers', Sellers' and Balanced Markets", Quarterly Journal of Economics, 110, 837-855. 